San Antonio Review • San Antonio Review (Issue 2 | Winter 2019)

\title{
Get On Your Knees
}

\section{Luis Cuauhtémoc Berriozábal}

Published on: May 18, 2019

Updated on: Aug 02, 2020

DOI: $10.21428 / 9 b 43 c d 98 . c 1343703$

License: Creative Commons Attribution 4.0 International License (CC-BY 4.0). 
In hell the beer is

never cold enough, the music is not loud enough, and a kiss gives you herpes.

What did you expect, the royal treatment? Get on your knees and crawl through the sharpest glass, the hottest coal, and remember what you did to get here.

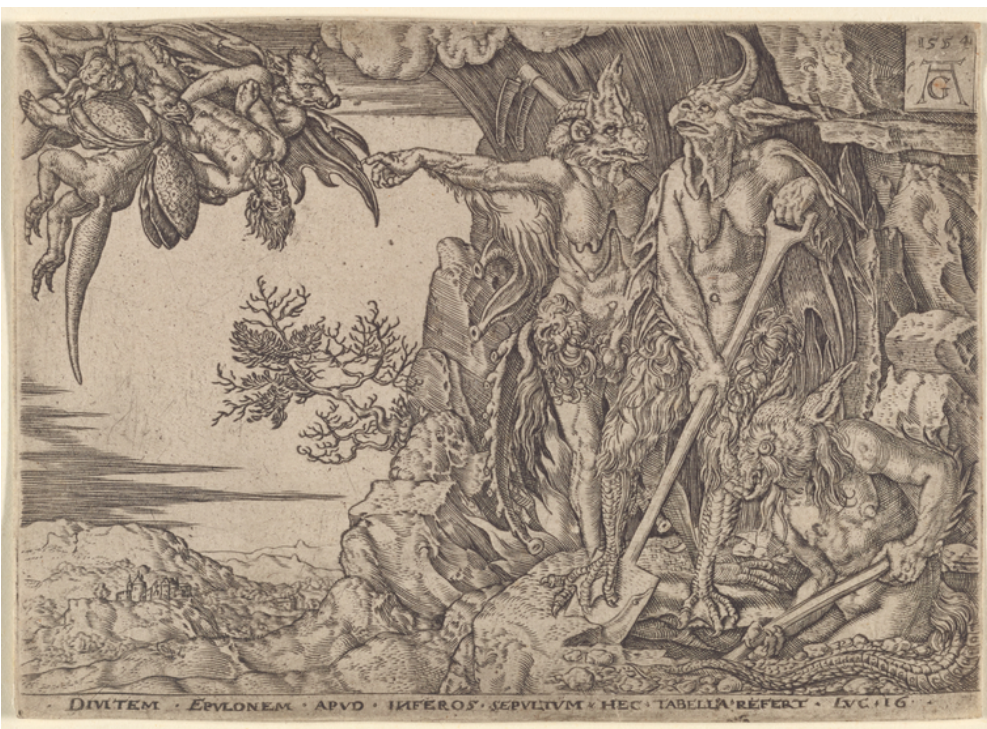

Print: "The Rich Man Transported to Hell" by Heinrich Aldegrever, 1554, public Enjoy your beer on earth, turn up the rock n' roll. It will not get better than this. Kiss the one you love and mean it. The sharp glass and hot coals are being made for you.

Luis Cuauhtémoc Berriozábal was born in Mexico and lives in Los Angeles, California, where he works in the mental health field. His latest chapbook, Make the Light Mine, was published by Kendra Steiner Editions. His first poetry book, Raw Materials, was published by Pygmy Forest Press. 